\title{
SÍNDROME DE BEHÇET: REPORTE DE CASO
}

\author{
BEHÇET SYNDROME: CASE REPORT
}

SÍNDROME DE BEHÇET: RELATO DE CASO

\section{CRISTINA HERRERA MORA}

Hospital de niños Roberto Gilbert Elizalde, Guayaquil, Ecuador

\begin{abstract}
La enfermedad de Behcet es una vasculitis de etiología desconocida, frecuente en los países de oriente, caracterizada por úlceras orales, genitales, uveítis y manifestaciones cutáneas. El propósito del presente artículo es reportar el caso de una patología infrecuente en el medio, así como realizar una revisión bibliográfica de la enfermedad. Se trata de un paciente de 14 años con cuadro clínico de evolución larvada, inicialmente presentó artritis la misma que fue recurrente y de difícil manejo pero no erosiva; y posteriormente presentó úlceras orales, lesiones pápulo-pustulosas, úlceras genitales y test de patergia positiva. Como describe la literatura, la artritis en este paciente no era erosiva, durante los períodos de inactividad no había limitación de ninguna articulación, y no respondió al metotrexate. Casi siempre la primera manifestación de la enfermedad de Behçet son las úlceras orales y no la artritis. El tiempo entre la aparición del primer síntoma y el diagnóstico así como en otras cohortes fue de 3 años. Dentro de los diagnósticos diferenciales de un paciente con artritis debe considerarse la enfermedad de Behçet. En Reumatología debe recalcarse la importancia de replantear los diagnósticos; considerando que estas enfermedades cursan con aparición lenta de los síntomas.
\end{abstract}

PALABRAS CLAVE: síndrome de Behçet, artritis, úlceras orales, uveítis.

ABSTRACT

Behçet's disease is a vasculitis of unknown etiology, common in eastern countries, characterized by oral and genital ulcers, uveitis, and skin manifestations. The purpose of this article is to report a case of rare pathology in the environment, as well as to carry out a bibliographic review of the disease. This is a 14-year-old patient with a clinical picture of larval evolution. He initially presented arthritis, which was recurrent and difficult to manage but not erosive; Later, he presented oral ulcers, papulopustular lesions, genital ulcers, and positive pathergy test. As described in the literature, arthritis in this patient was not erosive, during periods of inactivity, there was no limitation of any joint, and he did not respond to methotrexate. Oral ulcers are almost always the first manifestation of Behçet's disease and not arthritis. The time between the appearance of the first symptom and the diagnosis, as in other cohorts, was 3 years. Within the differential diagnoses of a patient with arthritis, Behçet's disease should be considered. In Rheumatology, the importance of rethinking the diagnoses must be emphasized; considering that these diseases occur with a slow onset of symptoms.

KEYWORDS: Behcet syndrome, arthritis, oral ulcer, uveitis.

RESUMO

A doença de Behçet é uma vasculite de etiologia desconhecida, comum em países orientais, caracterizada por úlceras orais e genitais, uveíte e manifestações cutâneas. 0 objetivo deste artigo é relatar o caso de uma patologia pouco frequente no meio ambiente, bem como realizar uma revisão bibliográfica sobre a doença. Trata-se de um paciente de 14 anos com quadro clínico de evolução larval, apresentando inicialmente artrite, que era recorrente e de difícil manejo, mas não erosiva; Posteriormente, apresentou úlceras orais, lesões papulopustulosas, úlceras genitais e teste de patergia positivo. Conforme descrito na literatura, a artrite neste paciente não era erosiva, durante os períodos de inatividade não havia limitação de nenhuma articulação e ele não respondeu ao metotrexato. As úlceras orais são quase sempre a primeira manifestação da doença de Behçet e não a artrite. 0 tempo entre 0 aparecimento do primeiro sintoma e o diagnóstico, como nas outras coortes, foi de 3 anos. Entre os diagnósticos diferenciais de um paciente com artrite, deve-se considerar a doença de Behçet. Na Reumatologia, a importância de repensar os diagnósticos deve ser enfatizada; considerando que essas doenças apresentam início lento dos sintomas.

PALAVRAS-CHAVE: síndrome de Behçet, artrite, úlceras orais, uveíte. 


\section{INTRODUCCION}

El propósito de la revisión del presente caso es reportar una patología infrecuente en el medio, así como hacer una revisión bibliográfica de la enfermedad de Behçet en niños. La enfermedad de Behçet es un desorden inflamatorio de causa desconocida, caracterizado por úlceras orales recurrentes, úlceras genitales, uveítis y lesiones dérmicas. El compromiso gastrointestinal, del sistema nervioso central y de los vasos de gran calibre es menos frecuente, pero compromete seriamente la vida. La prevalencia más alta de Behçet está dada en Turquía: 80 a 370 casos por 100.000 La media de edad es de 8 a 12 años, habiendo encontrado un promedio de 3 años entre el diagnóstico y la manifestación inicial de la enfermedad.1,2

La revisión bibliográfica se realizó con Pubmed y la base de datos Cochrane BVS, incluyendo como palabras clave: Behçet disease, children. De Cochrane se eligió solo un artículo de 14. En Pubmed se puso como filtro los tipos de artículos [case reports, clinical trials, guidelines, metanalysis, multicenter study, review], y el año de publicación [10 años]; de 94 artículos se eligieron 19.

El presente caso es la forma clásica de una enfermedad que es infrecuente en Occidente, y que debe ser pensada dentro del diagnóstico diferencial de un paciente con artritis. Se trata de un adolescente atendido por el servicio de reumatología del hospital Roberto Gilbert E. desde el año 2012 al año 2015; después de ello fue derivado a Reumatología de adultos. Como manifestación iniciala los 14 años de edad presentó artritis oligoarticular, posteriormente al año de seguimiento presentó aftas orales y lesiones máculopapulosas; a los 2 años las úlceras genitales y a los 3 años el test de patergia positivo.

REPORTE DE CASO

Paciente cuyo cuadro clínico inicia en agosto de 2011, a los 14 años de edad, con artritis de tobillo y rodilla izquierdos; datos de laboratorio reporta factor reumatoideo negativo, hipergammaglobulinemia y aumento de los reactantes de fase aguda (PCR 99,2 mg/L y eritrosedimentación $104 \mathrm{~mm} / \mathrm{h}$ ). Recibió prednisona y metotrexate oral con lo cual hubo mejoría de la artritis y disminución de los reactantes de fase aguda. El examen oftalmológico fue normal. En marzo de 2012 presentó lesiones papulopustulares en codos (Figura 1), acné y aftas orales (Figura 2); se añadió al tratamiento colchicina $1 \mathrm{mg} /$ día.
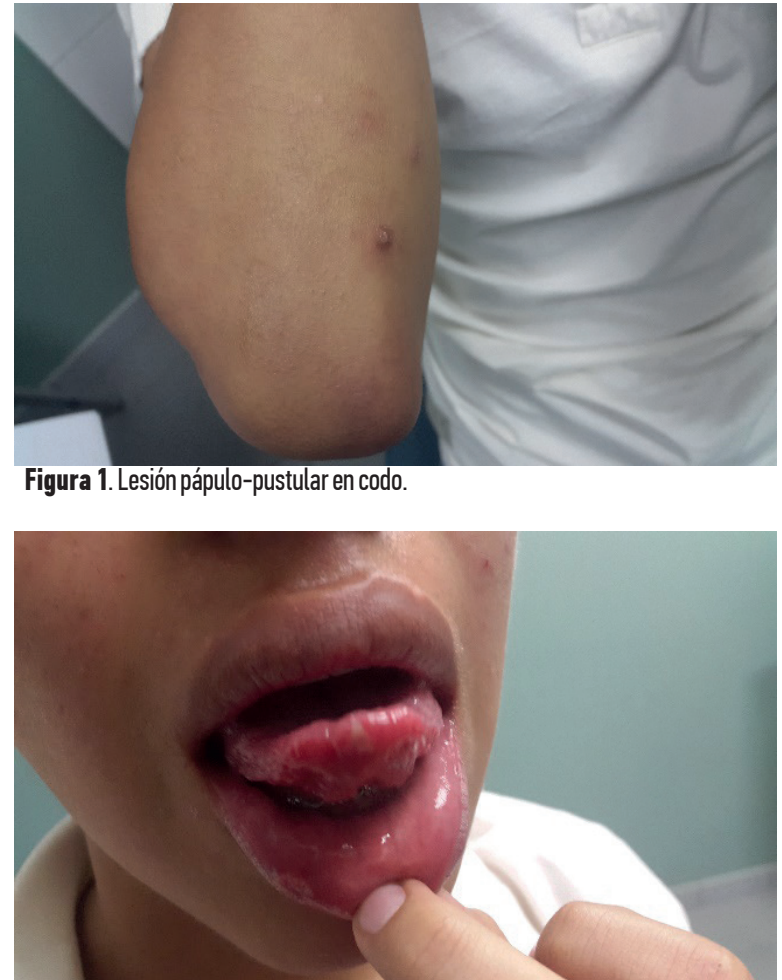

Figura 2. Úlceras orales indoloras en lengua y en labio.

El acné se asumió como propio de la edad. En enero de 2013 se suspendió el metotrexate por infecciones respiratorias recurrentes. En febrero 2013, el paciente seguía presentando aftas orales y se reactivó la artritis de rodilla, por ello se añadió leflunomide. Por refractariedad a los inmunosupresores habituales (persistencia de la artritis y las aftas orales); y corticorresistencia, se administró dos ciclos de rituximab $(375 \mathrm{mg} / \mathrm{m} 2$ semanal por 4 semanas) en abril y octubre 2013.

Durante el seguimiento tuvo: complemento normal, ANA negativo, HLA B27 negativo, anticuerpos extraíbles del nucleo negativos, VDRL negativo, función renal y hepática normales. Ecocardiograma normal. Por razones económicas, el paciente tomaba la medicación irregularmente, y suspendió la colchicina.

En septiembre 2014, a los 3 años de padecer la enfermedad, se añadió al cuadro clínico úlceras genitales que si bien no se hallaron en el examen físico, eran referidas por el paciente como recurrentes; el control anual de PPD fue positivo así como el test de patergia. Se descartó tuberculosis con una radiografía de tórax normal y PCR para Bacilo de Koch en esputo negativa. La artritis era principalmente en rodillas y no dejaba limitación en los períodos de inactividad. Se reclasificó la enfermedad del paciente como Enfermedad de Behçet por reunir los siguientes criterios: 
1. Úlceras en boca.

2. Úlceras en genitales visualizadas por el paciente.

3. Patergia positivo.

4. Lesiones papulopustulares y artritis oligoarticular no deformante.

La recaída se asumió ocasionada por la falta de adherencia al tratamiento. Se continuó con colchicina a $1,5 \mathrm{mg}$ por día, metilprednisolona 2 $\mathrm{mg}$ al día y leflunomide $20 \mathrm{mg}$ PO cada 24 horas con lo cual tuvo mejoría de los síntomas. Se derivó a adultos a los 18 años.

\section{DISCUSIÓN}

La enfermedad de Behçet es una vasculitis, de etiología desconocida; factores genéticos y ambientales han sido implicados en la etiología, pero no han sido probados. Es mucho más frecuente en los países del mediterráneo y asiáticos, en quienes se ha asociado al HLA B51 (en un 81\% de los casos). En América Latina, una cohorte mexicana reportó una asociación similar (no así en los norteamericanos), lo que puede deberse a un ancestro en común con los asiáticos por los procesos migratorios. ${ }^{1,3-8}$

Existen varias cohortes de pacientes publicados. ${ }^{9}$ La más grande es la publicada por Davatchi et al. tomada de la Cohorte Nacional Iraní de 6.500 pacientes (1975-2010), de los cuales 1973 eran niños; 5,1\% tenían entre 1-10 años y 25,3\% entre 11 y 20 años. ${ }^{10}$. La media de edad fue de 8 a 12 años. Excepcionalmente, la enfermedad puede debutar en neonatos hijos de madres con enfermedad activa durante el embarazo, dura poco tiempo y las manifestaciones son mucocutáneas. El retraso del diagnóstico es entre 3 a 5 años, debido a la rareza y la aparición lenta de los síntomas en los niños. En el paciente presente, el tiempo entre la aparición del primer síntoma y el diagnóstico fue de 3 años. ${ }^{2}$

Las manifestaciones clínicas incluyen: úlceras orales recurrentes, úlceras genitales, uveítis y lesiones dérmicas. Las úlceras orales aparecen en lengua, labios, carrillos, no dejan cicatriz y curan en 10 días. Usualmente es la manifestación inicial y es muy sensible, por ello ha sido tomado como criterio clasificatorio; sin embargo el 1-2\% de pacientes con Behçet no tienen úlceras orales. Las úlceras genitales son similares a las orales, pero más profundas y curan dejando cicatriz; son más específicas que las orales. ${ }^{4-6}$
En el presente caso, el síntoma inicial fue la artritis oligoarticular sin uveítis, ANA negativo y factor reumatoideo negativo. Llamaba la atención la eritrosedimentación alta y la ausencia de limitación en las articulaciones afectas; sin embargo, al no reunir inicialmente otros datos, se trató con corticoides y metotrexate.

Las lesiones cutáneas que aparecieron posteriormente eran papulonodulares, redondeadas, de $0,5 \mathrm{~cm}$ de diámetro. Al tratarse de un adolescente, el acné se asumió como propio de la edad. Con la aparición de las lesiones cutáneas y úlceras orales, sin ningún autoanticuerpo positivo, se pensó en un síndrome de superposición. En niños es frecuente la erupción papulopustular (39\%), y el eritema nodoso $(37 \%)$. Los adultos presentan seudofoliculitis y nódulos acneiformes; estos síntomas no son tomados en cuenta como criterios clasificatorios en adolescentes o en pacientes con corticoterapia prolongada. ${ }^{1,4}$

La artritis en pacientes con Behçet es oligo o poliarticular, se presenta en $22 \%$ de los niños y afecta a rodillas, tobillos, muñecas. ${ }^{1,4}$ Lo clásico es que no sea erosiva; sin embargo hay publicaciones que incluyen adultos con artritis erosiva. ${ }^{11}$

Dado que el test de patergia fue positivo, el PPD positivo se consideró un falso positivo. El test de patergia es criterio diagnóstico pero no es exclusivo de Behçet, también se presenta en el Síndrome de Sweet y en el pioderma gangrenoso. ${ }^{1}$

Las manifestaciones oculares incluyen uveítis anterior, posterior o panuveítis; el hipopión es raro en niños pero es característico de Behçet. En los niños la uveítis no suele ser la manifestación inicial como en los adultos, pero es mucho más agresiva. También puede comprometer retina, y producir disminución de la agudeza visual indolora. ${ }^{1,4}$

Otras manifestaciones incluyen al sistema nervioso central, gastrointestinal y vasculitis de pequeños vasos. Pueden presentar diarreas, melena, y a veces perforación intestinal; siendo esto poco frecuente en pediatría. La vasculitis ocurre en un 7 a $38 \%$ de los pacientes adultos y un $3,6 \%$ de pacientes pediátricos, más en varones. $(1,4)$, produciendo trombosis venosa superficial, profunda, tromboflebitis y aneurismas. La arteria más comprometida es la pulmonar. ${ }^{1,3,12} \mathrm{El}$ compromiso del sistema nervioso central ocurre 
en el $10-20 \%$ de los pacientes adultos y en un 3,6\% de pacientes pediátricos principalmente varones. Es causado ya sea por una lesión parenquimatosa neural (neuro Behçet) o secundaria al compromiso vascular (síndrome de Behçet vascular). Es una causa de morbimortalidad importante. Aunque es muy rara, está dentro del diagnóstico diferencial de enfermedades inflamatorias o desmielinizantes. No existe test diagnóstico para el Neuro-Behçet. Tampoco existe score validado para la evaluación clínica y el seguimiento. ${ }^{1,12}$

Respecto a la medicación usada en este paciente, tuvo respuesta parcial a los FARME's. Está descrito que para el compromiso mucocutáneo y articular, el uso de colchicina suele ser útil.,313 Cuando hay refractariedad de la uveítis, los biológicos más usados son el adalimumab, etanercept y rituximab; encontrando como más prometedor al adalimumab ${ }^{14-16}$. Sólo se encontró un caso reporte de un paciente con enfermedad de Behçet y compromiso articular en el cual usaron rituximab, obteniendo buenos resultados, ${ }^{17}$

El paciente continuó con metilprednisolona, leflunomide y se reinició la colchicina a $1,5 \mathrm{mg} /$ día. Hasta la fecha de su derivación a adultos, continuaba sin artritis, no había presentado uveítis, ni compromiso del SNC, ni gastrointestinal; las manifestaciones cutáneas habían mejorado, pero seguía presentandoúlceras orales y genitales con cierta frecuencia.

\section{CONCLUSIÓN Y RECOMENDACIÓN}

Durante el seguimiento de los pacientes con artritis siempre debe plantearse la posibilidad de reclasificar una enfermedad. Cuando la artritis oligoarticular es refractaria al uso de metotrexate y no deja limitaciones, se debe dudar del diagnóstico de artritis idiopática juvenil.

La enfermedad de Behçet debe pensarse en un paciente con artritis, úlceras orales y genitales, aunque esta enfermedad no sea tan frecuente en el medio, ni en la infancia. Aún faltan publicaciones que reúnan cohortes de pacientes con enfermedad de Behçet en América Latina.

\section{REFERENCIAS BIBLIOGRÁFICAS}

1. Sakane T, Takeno M, Suzuki N, Inaba G. Behçet Disease. N Engl J Med. 1999 Oct 21; 341(17):1284-91.

2. Piram M., Koné-Paut I. Maladie de Behçet de l'enfant. Rev Med Interne. 2014 Feb; 35(2):121-5.
3. Hatemi G, Yazici Y, Yazici H. Behçet Syndrome. Rheum Dis Clin North Am. 2013 May; 39(2):245-61.

4. Atmaca L, Boyvat A, Yalcindag F, Atmaca-Sonmez P, Gurler A. Behçet Disease in Children. Ocul Immunol Inflamm. 2011 Apr; 19(2):103-7.

5. Koné-Paut I, Yurdakul S, Bahabri SA, et al. Clinical features of Behçet's disease in children: An International Collaborative Study of 86 Cases. J Pediatr. 1998 Apr; 132(4):721-5.

6. Krause I, Uziel Y, Guedj D, et al. Childhood Behçet's Disease: Clinical Features And Comparison With Adult-Onset Disease. Rheumatology (Oxford). 1999 May; 38(5):457-62.

7. Lavalle C, Alarcón-Segovia D, Del Giudice-Knipping JA, Fraga A. Association of Behçet's syndrome with HLA-B5 in the Mexican mestizo population. J Rheumatol. 1981 Mar-Apr; 8(2):325-7.

8. Fujikawa S, Suemitsu T. Behçet Disease in Children: A Nationwide Retrospective Survey in Japan. Acta Paediatr Jpn. 1997; 39(2):285-9.

9. International Study Group for Behçet's Disease. Criteria for diagnosis of Behçet's Disease. Lancet. 1990 May 5;335(8697):1078-80.

10. Davatchi F, Shams H, Rezaipoor $M$ et al. Rituximab in intractable ocular lesions of Behcet's disease; randomized single-blind control study (pilot study). Int J Rheum Dis. 2010 Aug;13(3):246-52.

11. Frikha F, Marzouk S, Kaddour N, Frigui M, Bahloul Z. Destructive arthritis in Behçet's disease: a report of eight cases and literature review. Int J Rheum Dis. 2009 Sep;12(3):250-5.

12. Ait Ben Haddou EH, Imounan F, Regragui W et al. Neurological manifestations of Behçet disease: Evaluation of 40 patients treated by cyclophosphamide. Rev Neurol (Paris). 2012 Apr;168(4):344-9.

13. Yazici H, Pazarli H, Barnes C. et al. A controlled trial of Azathioprine in Behçet Syndrome. N Engl J Med. 1990 Feb 1;322(5):281-5.

14. Benitah NR, Sobrin L, Papaliodis GN. The use of biologic agents in the treatment of ocular manifestations of Behcet's disease. Semin Ophthalmol. 2011 JulSep;26(4-5):295-303.

15. Shapiro LS, Farrell J, Borhani Haghighi A. Tocilizumab treatment for neuro Behçet disease, the first report. Clin Neurol Neurosurg. 2012 Apr;114(3):297-8.

16. Lee JH, Cheon JH, Jeon SW et al. Efficacy of infliximab in intestinal Behçet's disease: a Korean multicenter retrospective study. Inflamm Bowel Dis. 2013 Aug;19(9):1833-8.

17. Zhao BH, Oswald AE. Improved clinical control of a challenging case of Behçet's disease with rituximab therapy. Clin Rheumatol. 2014 Jan;33(1):149-50. 